\title{
Bleeding in Liver \\ Surgery: Prevention and Treatment
}

Edris M. Alkozai, BSc, Ton Lisman, PhD, Robert J. Porte, MD, PhD *

\section{KEYWORDS}

- Blood loss • Liver transplantation • Liver resection

- Surgical methods • Central venous pressure • Fibrin sealants

- Aprotinin • Tranexamic acid

Bleeding in major surgical procedures involving the liver, such as partial liver resection and liver transplantation, occurs almost inevitably. Although blood loss in patients undergoing liver surgery has decreased substantially during the last decade, excessive blood loss can still be a major concern in individual patients. Bleeding problems are not limited to surgical patients who have a cirrhotic liver; they may also occur in patients who have a normal liver. Extensive bleeding may require the transfusion of blood or blood products, which are associated with increased rates of morbidity and mortality. ${ }^{1-6}$ Although the mechanism of bleeding in surgical interventions is multifactorial, technical factors may be responsible for a significant amount of intraoperative and early postoperative bleeding. ${ }^{7}$ Besides surgical factors, abnormalities of the hemostatic system can contribute to bleeding during liver surgery. Hemostatic function is determined by the interaction of the vascular wall, platelets, coagulation factors, and fibrinolytic function. All these components of the hemostatic system may be abnormal in patients who have a compromised liver function, and this may contribute to excessive bleeding during liver surgery. ${ }^{8,9}$ However, despite the multiple laboratory abnormalities in the hemostatic system, patients who have cirrhosis can nowadays undergo major surgical procedures such as liver transplantation or partial liver resection without transfusion of blood products. ${ }^{9}$ Although part of this can be explained by important advances in surgical methods and techniques, it may also imply that the detected abnormalities in laboratory tests of the hemostatic system are (not always) clinically relevant. Indeed, several investigators have shown that preoperative conventional coagulation assays are a poor predictor of blood loss during liver transplantation. ${ }^{10,11}$ In addition, the correction of a prolonged prothrombin time with

Department of Surgery, Section of Hepatobiliary Surgery and Liver Transplantation, University Medical Center Groningen, University of Groningen, P.O. Box 30.001, 9700 RB Groningen, The Netherlands

* Corresponding author.

E-mail address: r.j.porte@chir.umcg.nl (R.J. Porte). 
recombinant factor VIla has not been shown to lead to a reduction in blood loss or transfusion requirements in patients undergoing major liver surgery. ${ }^{12,13}$

The main progress in reducing perioperative blood loss has been made through improved surgical and anesthetic techniques and through better understanding of hemostatic disorders in patients who have liver disease. ${ }^{7,14}$ The purpose of this article is to provide a clinically oriented guide to the prevention and treatment of bleeding in liver surgery. The authors discuss the developments in surgical, anesthesiologic, and pharmacologic strategies that have contributed to a reduction of blood loss during liver surgery in cirrhotic and noncirrhotic patients. The clinical relevance of different types of strategies may vary, depending on the stage of the operation. For example, topical hemostatic agents have a role in reducing blood loss from the hepatic resection surface after partial liver resection, whereas surgical techniques play a more important role during transsection of the liver parenchyma (Fig. 1).

\section{SURGICAL STRATEGIES TO REDUCE BLOOD LOSS}

Refinements in surgical techniques and better understanding of the liver anatomy have provided important contributions to the reduction of blood loss during liver surgery. In recent years, several new techniques have been developed to perform more complex surgical interventions in patients who have a pre-existing bleeding risk, such as patients who have liver cirrhosis (Box 1). In addition, improvements in the preoperative imaging and evaluation of the liver function reserve have contributed to a better selection of patients and a lower overall postoperative morbidity and mortality. ${ }^{15,16}$

Blood loss during a partial liver resection may vary during the three stages of the procedure (see Fig. 1). The first stage, in which the efferent and afferent vessels of the part of the liver that needs to be resected are identified, is characterized by minor

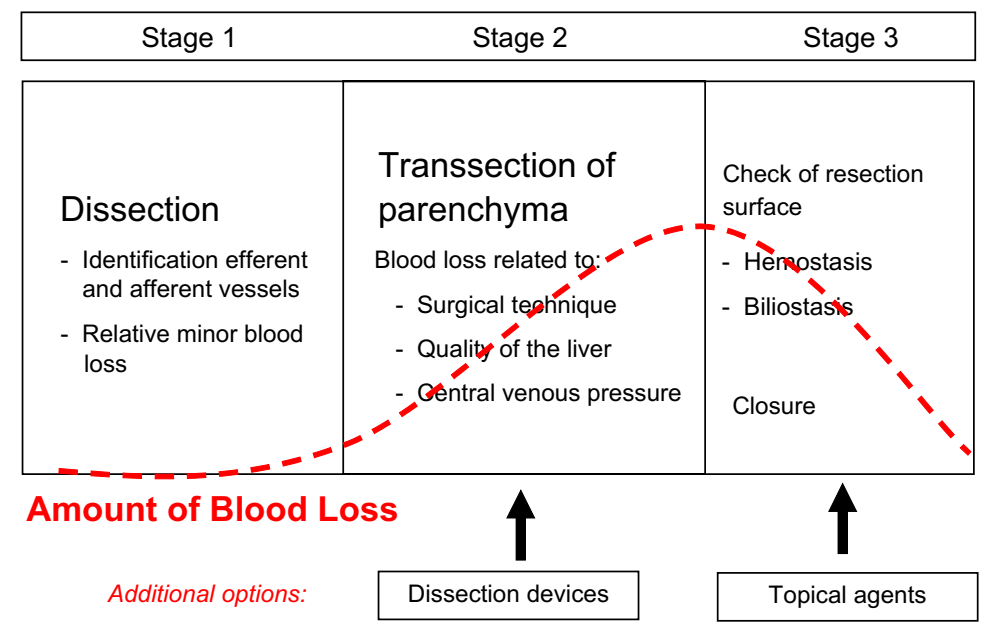

Fig. 1. The mechanisms of bleeding and the relative amount of blood loss (dotted line) during the three surgical stages of partial liver resections. In general, most bleeding can be encountered during transsection of the liver parenchyma. In this stage of the operation, blood loss is mainly caused by bleeding from the resection surface of the liver. Volume contraction and a low intravascular filling status (ie, low central venous pressure) are generally more effective in reducing blood loss in this stage than massive transfusion of blood products such as fresh-frozen plasma. 
Box 1

Surgical and anesthesiologic methods used to reduce blood loss in liver surgery

Surgical

Vascular clamping techniques

Inflow occlusion

Continuous Pringle maneuver

Continuous Pringle maneuver after ischemic preconditioning

Intermittent Pringle maneuver

Total vascular occlusion

Dissection devices for transsection of liver parenchyma

Classic methods

Scalpel

"Finger-fracture" method

Clamp crushing

Ultrasonic dissection

Hydro-jet dissection

Electro coagulation (Argon coagulation)

Radiofrequency ablation-based devices

Topic hemostatic agents

Anesthesiologic

Maintaining low central venous pressure by using

Volume contraction

Phlebotomy

Vasodilatation

If needed, forced diuresis

Blood products

Use of pharmacologic agents

Antifibrinolytics

Recombinant factor VIla

blood loss. An exception may be patients who have intra-abdominal adhesions caused by previous abdominal surgery and patients who have significant portal hypertension, who generally have a higher bleeding tendency. In general, the amount of surgical blood loss is the highest in the second stage of liver resection, when transsection of the parenchyma is performed. In this stage, the quality of the liver tissue, the dissection method used, and the central venous pressure (CVP) may influence the extent of blood loss. Selective vascular occlusion techniques have an important role in controlling blood loss in this stage of the operation, as was recently discussed elsewhere. ${ }^{17-20}$ Van der Belt and colleagues ${ }^{20}$ studied the application of vascular occlusion methods by sending a questionnaire to 621 surgeons in Europe. Although the overall response rate was low (50\%), this study provided good insight into current practice. Most of the responding surgeons indicated that clamping of the liver 
vasculature is used selectively when excessive blood loss occurs during hepatic resection. Complete inflow occlusion (ie, the Pringle maneuver) is the most frequently applied method in this situation. Similar results have been reported by Nakajima and colleagues, ${ }^{21}$ based on a survey of 231 hospitals in Japan. A disadvantage of using vascular inflow occlusion is the resulting ischemic injury of the liver. Intermittent clamping or ischemic preconditioning may decrease the amount of ischemic injury, especially in cirrhotic livers. ${ }^{21,22}$ However, intermittent clamping is also associated with more bleeding than continuous clamping. ${ }^{22}$ Nevertheless, it is the most frequently applied method of vascular occlusion in Europe. ${ }^{20}$

In addition to vascular inflow occlusion techniques, several new methods and devices for transsection of the liver parenchyma have been developed (see Box 1). The Cavitron Ultrasonic Surgical Aspirator (CUSA) is the most frequently used device, followed by precoagulation devices. ${ }^{20,21}$ Although most of these devices may contribute to a reduction of blood loss during the transsection phase, some of them perform slowly and some groups have reported disappointing results. ${ }^{22,23}$ In a prospective randomized clinical trial, Lesurtel and colleagues ${ }^{24}$ compared four techniques of liver transsection in 100 noncirrhotic patients undergoing major liver resections. The conventional clamp-crashing technique was compared with CUSA, Hydro-jet, and a dissecting sealer. ${ }^{25}$ In this study, the clamp-crashing technique was associated with significantly lower blood loss, shorter resection time, and lower costs, compared with the other three techniques. So, all in all, the beneficial effects of these new devices are not entirely clear and more prospective studies will be needed to assess the role of these devices in liver surgery. In the absence of a strong advantage of any of these transsection devices, personal preference and local availability are the main factors that determine the use of a given device in a center.

\section{ANESTHESIOLOGIC STRATEGIES TO REDUCE BLOOD LOSS}

The impact of anesthesiologic care on blood loss and transfusion requirement in patients undergoing major liver surgery is mainly determined by (1) intraoperative fluid management, (2) the transfusion triggers used, and (3) the use of pharmacologic agents (the last of which will be discussed below).

Transfusion of blood products may be required in the case of active and serious bleeding, but the value of the prophylactic use of blood products, such as fresh-frozen plasma (FFP), is currently being debated. ${ }^{25-27}$ The use of blood products, however, is highly variable and not always evidence based. For example, studies in patients undergoing liver transplantation have shown a large variability in the use of blood products among different centers and even among individual anesthesiologists within centers. ${ }^{27}$ Although excessive bleeding may, and should, be managed by the transfusion of blood products, such as FFP, platelet concentrates, and packed red blood cells (RBC), ${ }^{28}$ it is also becoming clear that no consensus currently exists on transfusion practice in liver surgery. Prospective, multicenter studies with predetermined hemostasis assessment and transfusion guidelines are needed and would improve our understanding of the correction and prevention of massive bleeding during liver surgery, with likely improvements in patient outcomes. ${ }^{29}$

In addition to monitoring and correcting blood loss and associated metabolic abnormalities, anesthesiologists play a key role in reducing blood loss during liver surgery by maintaining a low CVP. Performance of surgical practice under low CVP is one of the strategies that have been studied intensively in liver surgery. ${ }^{30-33}$ Although already suggested by Bismuth and colleagues, ${ }^{33}$ Jones and colleagues ${ }^{32}$ were the first to show that blood loss during liver resection is almost linearly related to the 
CVP. Low CVP ( $<5 \mathrm{~mm} \mathrm{Hg}$ ) can be achieved by applying volume contraction, by using vasodilating agents, or by stimulation of forced diuresis (see Box 1). Volume contraction has been suggested as a safe method of reducing blood loss during liver surgery. It can be achieved by a restrictive use of fluid and blood products, avoidance of fluid overload, and no routine correction of abnormal coagulation tests by infusion of FFP or other large-volume blood products. ${ }^{2,4,31}$ Although a low CVP is associated with reduced blood loss, it also carries a higher risk for complications such as air embolism, systemic tissue hypoperfusion, and renal failure. . $^{230,34,35}$ Schroeder and colleagues ${ }^{34}$ studied the safety of a fluid restriction policy and low CVP in liver transplant recipients by comparing outcome variables in two centers with different policies. One center had the policy to aim for a low CVP $(<5 \mathrm{~mm} \mathrm{Hg})$ by using fluid restriction, whereas the second center did not take any specific measures to lower the CVP and aimed for normal CVP policy $(7-10 \mathrm{~mm} \mathrm{Hg})$. Both patient groups were similar in demographics, cause of liver disease, and surgical methods. The low CVP group received lower amounts of RBC (3.8 versus 11.6 units, $P<.01$ ), FFP (1.3 versus 14.7 units, $P<.001)$, and platelets ( 0.6 versus 2.4 units, $P<.001)$ compared with the normal CVP group. However, the postoperative peak serum creatinine level $(3.2$ versus $1.8 \mathrm{mg} / \mathrm{dL}, P<.01)$, the need for dialysis $(6.8 \%$ versus $1.2 \%, P<.05)$, and 30 -day mortality $(6[8.2 \%]$ versus $0, P<.05)$ were higher in patients who had low CVP. A limitation of this study is the lack of randomization and the comparison of two centers, which may have differed in many other aspects than just a CVP target. Contrary to the study by Schroeder and colleagues, Wang and colleagues ${ }^{36}$ found no detrimental effect on maintaining a low CVP in a prospective study of 50 cirrhotic patients undergoing partial liver resection for hepatocellular carcinoma. Patients were divided into an intervention group $(n=25)$, in which the CVP was maintained at less than or equal to $4 \mathrm{~mm} \mathrm{Hg}$, and a control group $(n=25)$ with normal CVP. Intraoperative blood loss was significantly lower in the group with low CVP, compared with the control group (903 $\pm 180 \mathrm{~mL}$ versus $2329 \pm 2538 \mathrm{~mL}, P<.01$ ). In addition, $\mathrm{RBC}$ and FFP transfusion requirements were significantly lower and hospital stay was shorter in the group with low CVP, whereas no negative effect was found in postoperative hepatic and renal function.

Some groups have taken the concept of fluid contraction much further than only reducing fluid infusions, and these groups even performed phlebotomy as a strategy to minimize intraoperative blood loss in patients undergoing major liver surgery. ${ }^{35,37}$ Hashimoto and colleagues ${ }^{37}$ performed a randomized controlled trial in 79 healthy participants who underwent partial liver resection for living donor liver transplantation. Participants were randomly allocated to a blood withdrawal group ( $n=40$, collecting a volume of blood corresponding to $0.7 \%$ of the patient's body weight) or a control group ( $n=39$ ) with no blood withdrawal. Surgeons were blinded for the allocated groups. The CVP at the beginning of the parenchymal transsection was significantly lower in the group with blood withdrawal (median 5 [range 2-9] $\mathrm{cm} \mathrm{H}_{2} \mathrm{O}$ versus 6 [range 2-13] $\left.\mathrm{cm} \mathrm{H}_{2} \mathrm{O}, P=.005\right)$ compared with controls. Blood loss during liver transsection was also significantly lower in the phlebotomized group (140 [range 40-430] mL versus 230 [range 40-660] $\mathrm{mL}, P=.034$ ). However, the two showed no statistical difference in postoperative outcomes. In another prospective study, Massicotte and colleagues ${ }^{35}$ examined the effect of maintaining a low CVP through volume contraction and by using intraoperative phlebotomy in patients undergoing liver transplantation. Outcome in these patients was compared with outcome in a historical control group without phlebotomy. ${ }^{26}$ Intraoperative blood loss was significantly lower in the prospective group with a low CVP (903 $\pm 582 \mathrm{~mL}$ versus $1479 \pm 1750 \mathrm{~mL}, P=.001)$, and no patient required dialysis in the postoperative period. 
In general, evidence is increasing that blood loss during major liver surgery is strongly influenced by the filling status and CVP of the patient. Measures to reduce the filling status of the patient and to lower the CVP through volume contraction and no routine correction of laboratory coagulation test with large-volume blood products is effective and safe. Larger prospective studies will be needed to define the exact role and safety of blood withdrawal as a measure of reducing the CVP and minimizing blood loss during liver surgery.

\section{PHARMACOLOGIC STRATEGIES TO REDUCE BLOOD LOSS}

Several pharmacologic measures are available to treat or prevent bleeding complications during liver surgery. However, these agents should only be used as complementary to other methods in reducing blood loss. Three main categories can be recognized: topical hemostatic agents, antifibrinolytic drugs, and procoagulant drugs. $^{38}$

\section{Topical Hemostatic Agents}

Topical agents may be useful to stimulate hemostasis at the resection surface of the liver after parenchymal transsection. Based on their working mechanism, topical agents can be divided into three groups: agents that mimic coagulation (ie, fibrin sealants), agents that provide a matrix for endogenous coagulation (ie, collagen, gelatin, and cellulose sponges), and combined products that work as a matrix for endogenous and exogenous coagulation factors. ${ }^{38,39}$ Current scientific evidence suggests beneficial effects in reducing the time to hemostasis and in lowering the requirements for perioperative RBC transfusions. ${ }^{39-43}$ Although the beneficial effects of fibrin sealants have also been confirmed in a recent Cochrane review, ${ }^{44}$ the efficacy of fibrin sealant in liver surgery has recently been questioned. ${ }^{45}$ In a large, randomized, controlled trial in 300 patients undergoing partial liver resection, Figueras and associates ${ }^{45}$ found no difference in total blood loss, transfusion requirements, or postoperative morbidity between patients treated with fibrin sealants $(n=150)$ and a control group without fibrin sealants $(n=150)$.

\section{Antifibrinolytics}

Antifibrinolytics can be categorized into two groups: inhibitors of plasminogen (lysine analogs tranexamic acid and epsilon-aminocaproic acid), and inhibitors of plasmin (serine protease inhibitors aprotinin and nafamostat mesylate). In recent years, several studies and reviews have been published on the efficacy and safety of antifibrinolytics in liver surgery and transplantation. ${ }^{14,38,46-49}$ In liver transplantation, aprotinin and tranexamic acid have been shown to result in a significant reduction in blood loss and transfusion requirements of around $30 \%$ to $40 \% .{ }^{50}$ Because of recent safety concerns, especially a higher risk for renal failure and perioperative death in patients who were given aprotinin during cardiac surgery, marketing of aprotinin has recently been suspended. However, in the liver transplant population, prospective studies have not caused any safety concerns, and no increased risk for thromboembolic events or renal failure has been noted in liver transplant patients treated with aprotinin. ${ }^{50,51}$ Although antifibrinolytics have been studied extensively in liver transplantation, only two prospective studies have examined the efficacy in patients undergoing liver resections. ${ }^{52,53}$ In general, improvements in surgical technique and anesthesiologic care seem to be more important in reducing blood loss in patients undergoing partial liver resections than the use of the antifibrinolytic drugs. Antifibrinolytics may be indicated in 
a selected group of patients who have cirrhosis and are undergoing liver resection, but further studies in this specific group of patients will be needed. ${ }^{54}$

\section{Procoagulant Drugs}

The efficacy and safety of the recombinant factor VIla has been studied in several randomized clinical trials in cirrhotic and noncirrhotic patients undergoing partial liver resections or transplantation. ${ }^{12,13,55-57}$ Although these studies did not cause major safety concerns, ${ }^{38,58,59}$ they also failed to demonstrate a significant difference in blood loss or transfusion requirements between patients who received recombinant factor VIla or placebo. In all of these studies, recombinant factor VIla was used as a prophylactic drug, which may not be the most efficient use for this drug. Probably, this drug should be seen more as a drug that can be used a "rescue therapy" to control bleeding in situations of major bleeding where other therapies have failed. More research in this area is needed.

\section{SUMMARY}

In general, perioperative blood loss and blood transfusions have a negative impact on postoperative outcome after liver surgery. Surgical technique and experience are key factors determining the amount of blood loss in liver surgery. Inflow occlusion (the Pringle maneuver) and the use of low CVP are simple and effective measures of reducing blood loss during parenchyma transsection. No superiority of one dissection device has been shown above the others, and their use depends mainly on the quality of the liver parenchyma and personal preference and experience. The emerging evidence indicates that abnormal coagulation tests do not predict bleeding in cirrhotic patients. Preprocedural correction of coagulation tests with blood products has not been shown to reduce intraoperative bleeding and it even seems counterproductive because it results mainly in an increase of the intravascular filling status of the patient, which may, in fact, enhance the bleeding risk. Factors such as portal hypertension and the hyperdynamic circulation in patients who have cirrhosis may play a more important role in the bleeding tendency of these patients. Therefore, volume contraction, rather than prophylactic transfusion blood products (ie, FFP), seems justified in patients undergoing major liver surgery. An increasing number of studies suggest that volume contraction in these patients is safe and effective in reducing perioperative blood loss and transfusion requirements. Although antifibrinolytic drugs proved to be effective in reducing blood loss during liver transplantation, topical or systemic hemostatic drugs are of limited value in reducing blood loss in patients undergoing partial liver resections.

\section{REFERENCES}

1. Hendriks HG, van der MJ, De Wolf JT, et al. Intraoperative blood transfusion requirement is the main determinant of early surgical re-intervention after orthotopic liver transplantation. Transpl Int 2005;17:673-9.

2. Cacciarelli TV, Keeffe EB, Moore DH, et al. Effect of intraoperative blood transfusion on patient outcome in hepatic transplantation. Arch Surg 1999;134:25-9.

3. Stainsby D, Williamson L, Jones $\mathrm{H}$, et al. 6 Years of shot reporting-its influence on UK blood safety. Transfus Apheresis Sci 2004;31:123-31.

4. de Boer MT, Molenaar IQ, Hendriks HG, et al. Minimizing blood loss in liver transplantation: progress through research and evolution of techniques. Dig Surg 2005;22:265-75. 
5. Porte RJ, Hendriks HG, Slooff MJ. Blood conservation in liver transplantation: the role of aprotinin. J Cardiothorac Vasc Anesth 2004;18:31S-7S.

6. Ramos E, Dalmau A, Sabate A, et al. Intraoperative red blood cell transfusion in liver transplantation: influence on patient outcome, prediction of requirements, and measures to reduce them. Liver Transpl 2003;9:1320-7.

7. Marietta M, Facchini L, Pedrazzi $P$, et al. Pathophysiology of bleeding in surgery. Transplant Proc 2006;38(3):812-4. Ref Type: Hearing.

8. Porte RJ, Knot EA, Bontempo FA. Hemostasis in liver transplantation. Gastroenterology 1989;97:488-501.

9. Lisman T, Leebeek FW. Hemostatic alterations in liver disease: a review on pathophysiology, clinical consequences, and treatment. Dig Surg 2007;24: 250-8.

10. Findlay JY, Rettke SR. Poor prediction of blood transfusion requirements in adult liver transplantations from preoperative variables. J Clin Anesth 2000;12:319-23.

11. Steib A, Freys G, Lehmann C, et al. Intraoperative blood losses and transfusion requirements during adult liver transplantation remain difficult to predict. Can $\mathrm{J}$ Anaesth 2001;48:1075-9.

12. Lodge JP, Jonas S, Oussoultzoglou E, et al. Recombinant coagulation factor VIla in major liver resection: a randomized, placebo-controlled, double-blind clinical trial. Anesthesiology 2005;102:269-75.

13. Planinsic RM, van der MJ, Testa G, et al. Safety and efficacy of a single bolus administration of recombinant factor VIla in liver transplantation due to chronic liver disease. Liver Transpl 2005;11:895-900.

14. Groenland TH, Porte RJ. Antifibrinolytics in liver transplantation. Int Anesthesiol Clin 2006;44:83-97.

15. Friedman LS. The risk of surgery in patients with liver disease. Hepatology 1999; 29:1617-23.

16. Suman A, Carey WD. Assessing the risk of surgery in patients with liver disease. Cleve Clin J Med 2006;73:398-404.

17. van Gulik TM, de GW, Dinant S, et al. Vascular occlusion techniques during liver resection. Dig Surg 2007;24:274-81.

18. Smyrniotis V, Farantos C, Kostopanagiotou G, et al. Vascular control during hepatectomy: review of methods and results. World J Surg 2005;29:1384-96.

19. Dixon E, Vollmer CM Jr, Bathe OF, et al. Vascular occlusion to decrease blood loss during hepatic resection. Am J Surg 2005;190:75-86.

20. van der Bilt JD, Livestro DP, Borren A, et al. European survey on the application of vascular clamping in liver surgery. Dig Surg 2007;24:423-35.

21. Nakajima Y, Shimamura T, Kamiyama T, et al. Control of intraoperative bleeding during liver resection: analysis of a questionnaire sent to 231 Japanese hospitals. Surg Today 2002;32:48-52.

22. Selzner N, Rudiger H, Graf R, et al. Protective strategies against ischemic injury of the liver. Gastroenterology 2003;125:917-36.

23. Takayama T, Makuuchi M, Kubota K, et al. Randomized comparison of ultrasonic vs clamp transection of the liver. Arch Surg 2001;136:922-8.

24. Lesurtel M, Selzner M, Petrowsky H, et al. How should transection of the liver be performed?: a prospective randomized study in 100 consecutive patients: comparing four different transection strategies. Ann Surg 2005;242:814-22 [discussion].

25. Lisman T, Caldwell SH, Porte RJ, et al. Consequences of abnormal hemostasis tests for clinical practice. J Thromb Haemost 2006;4:2062-3. 
26. Massicotte L, Sassine MP, Lenis S, et al. Transfusion predictors in liver transplant. Anesth Analg 2004;98:1245-51, table.

27. Ozier Y, Pessione F, Samain E, et al. Institutional variability in transfusion practice for liver transplantation. Anesth Analg 2003;97:671-9.

28. Kang Y, Audu P. Coagulation and liver transplantation. Int Anesthesiol Clin 2006; 44:17-36.

29. Lopez-Plaza I. Transfusion guidelines and liver transplantation: time for consensus. Liver Transpl 2007;13:1630-2.

30. Melendez JA, Arslan V, Fischer ME, et al. Perioperative outcomes of major hepatic resections under low central venous pressure anesthesia: blood loss, blood transfusion, and the risk of postoperative renal dysfunction. J Am Coll Surg 1998;187:620-5.

31. Smyrniotis V, Kostopanagiotou G, Theodoraki K, et al. The role of central venous pressure and type of vascular control in blood loss during major liver resections. Am J Surg 2004;187:398-402.

32. Jones RM, Moulton CE, Hardy KJ. Central venous pressure and its effect on blood loss during liver resection. Br J Surg 1998;85:1058-60.

33. Bismuth $\mathrm{H}$, Castaing D, Garden OJ. Major hepatic resection under total vascular exclusion. Ann Surg 1989;210:13-9.

34. Schroeder RA, Collins BH, Tuttle-Newhall E, et al. Intraoperative fluid management during orthotopic liver transplantation. J Cardiothorac Vasc Anesth 2004; 18:438-41.

35. Massicotte L, Lenis S, Thibeault L, et al. Effect of low central venous pressure and phlebotomy on blood product transfusion requirements during liver transplantations. Liver Transpl 2006;12:117-23.

36. Wang WD, Liang LJ, Huang $X Q$, et al. Low central venous pressure reduces blood loss in hepatectomy. World J Gastroenterol 2006;12:935-9.

37. Hashimoto T, Kokudo N, Orii R, et al. Intraoperative blood salvage during liver resection: a randomized controlled trial. Ann Surg 2007;245:686-91.

38. Porte RJ, Leebeek FW. Pharmacological strategies to decrease transfusion requirements in patients undergoing surgery. Drugs 2002;62:2193-211.

39. Berrevoet $F$, de HB. Use of topical hemostatic agents during liver resection. Dig Surg 2007;24:288-93.

40. Heaton N. Advances and methods in liver surgery: haemostasis. Eur J Gastroenterol Hepatol 2005;17(Suppl 1):S3-12.

41. Chapman WC, Clavien PA, Fung J, et al. Effective control of hepatic bleeding with a novel collagen-based composite combined with autologous plasma: results of a randomized controlled trial. Arch Surg 2000;135: 1200-4.

42. Schwartz M, Madariaga J, Hirose R, et al. Comparison of a new fibrin sealant with standard topical hemostatic agents. Arch Surg 2004;139: 1148-54.

43. Jackson MR. Fibrin sealants in surgical practice: an overview. Am J Surg 2001; 182:1S-7S.

44. Carless PA, Henry DA, Anthony DM. Fibrin sealant use for minimising peri-operative allogeneic blood transfusion. Cochrane Database Syst Rev 2003;1: CD004171.

45. Figueras J, Llado L, Miro M, et al. Application of fibrin glue sealant after hepatectomy does not seem justified: results of a randomized study in 300 patients. Ann Surg 2007;245:536-42. 
46. Xia VW, Steadman $\mathrm{RH}$. Antifibrinolytics in orthotopic liver transplantation: current status and controversies. Liver Transpl 2005;11:10-8.

47. Ozier $Y$, Schlumberger S. Pharmacological approaches to reducing blood loss and transfusions in the surgical patient. Can J Anaesth 2006;53:S21-9.

48. Henry DA, Carless PA, Moxey AJ, et al. Anti-fibrinolytic use for minimising perioperative allogeneic blood transfusion. Cochrane Database Syst Rev 2007;4: CD001886.

49. Dalmau A, Sabate A, Acosta F, et al. Tranexamic acid reduces red cell transfusion better than epsilon-aminocaproic acid or placebo in liver transplantation. Anesth Analg 2000;91:29-34.

50. Molenaar IQ, Warnaar N, Groen H, et al. Efficacy and safety of antifibrinolytic drugs in liver transplantation: a systematic review and meta-analysis. Am J Transplant 2007; 7:185-94.

51. Warnaar N, Mallett SV, de Boer MT, et al. The impact of aprotinin on renal function after liver transplantation: an analysis of 1,043 patients. Am J Transplant 2007;7: 2378-87.

52. Lentschener C, Benhamou D, Mercier FJ, et al. Aprotinin reduces blood loss in patients undergoing elective liver resection. Anesth Analg 1997;84:875-81.

53. Wu CC, Ho WM, Cheng SB, et al. Perioperative parenteral tranexamic acid in liver tumor resection: a prospective randomized trial toward a "blood transfusion"-free hepatectomy. Ann Surg 2006;243:173-80.

54. Pereboom IT, de Boer MT, Porte RJ, et al. Aprotinin and nafamostat mesilate in liver surgery: effect on blood loss. Dig Surg 2007;24:282-7.

55. Lodge JP, Jonas S, Jones RM, et al. Efficacy and safety of repeated perioperative doses of recombinant factor VIla in liver transplantation. Liver Transpl 2005;11: 973-9.

56. Hendriks HG, Meijer K, de Wolf JT, et al. Reduced transfusion requirements by recombinant factor VIIa in orthotopic liver transplantation: a pilot study. Transplantation 2001;71:402-5.

57. Meijer K, Hendriks HG, de Wolf JT, et al. Recombinant factor VIla in orthotopic liver transplantation: influence on parameters of coagulation and fibrinolysis. Blood Coagul Fibrinolysis 2003;14:169-74.

58. Vincent JL, Rossaint R, Riou B, et al. Recommendations on the use of recombinant activated factor VII as an adjunctive treatment for massive bleeding-a European perspective. Crit Care 2006;10(4):R120.

59. Levy JH, Fingerhut A, Brott $\mathrm{T}$, et al. Recombinant factor VIla in patients with coagulopathy secondary to anticoagulant therapy, cirrhosis, or severe traumatic injury: review of safety profile. Transfusion 2006;46:919-33. 